\title{
Evidence for non-coaxiality of ferrimagnetic and paramagnetic fabrics, developed during magma flow and cooling in a thick mafic dyke
}

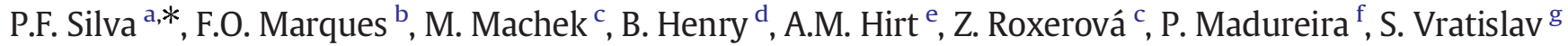 \\ a ISEL and IDL (Univ. Lisbon), Lisbon, Portugal \\ b University of Lisbon, Lisbon, Portugal \\ c Institute of Geophysics AS CR, v.v.i, Boční II/1401, 14131, Prague 4, Czech Republic \\ d Paléomagnétisme, Institut de Physique du Globe de Paris, Sorbonne Paris Cité, Université Paris Diderot, UMR 7154 CNRS, 94107 Saint-Maur cedex, France \\ e Laboratory of Natural Magnetism, Institute of Geophysics, ETH-Zürich, CH-8092 Zurich, Switzerland \\ ${ }^{f}$ EMEPC, 2770-047 Paço d'Arcos and University of vora, D. Geocincias and C. Geofisica de vora, 7000-671 vora, Portugal \\ ${ }^{\mathrm{g}}$ Laboratory of Neutron Diffraction, Department of Solid State Engineering, Faculty of Nuclear Sciences and Physical Engineering, CTU in Prague, Czech Republic
}

\section{a r t i cle info}

\section{Article history:}

Received 3 October 2013

Received in revised form 26 February 2014

Accepted 8 April 2014

Available online 21 April 2014

\section{Keywords:}

Paramagnetic

Ferrimagnetic

Fabrics

Microstructures

Dyke emplacement

Stress field

\begin{abstract}
a b s t r a c t
A detailed analysis of fabrics of the chilled margin of a thick dolerite dyke (Foum Zguid dyke, Southern Morocco) was performed in order to better understand the development of sub-fabrics during dyke emplacement and cooling. AMS data were complemented with measurements of paramagnetic and ferrimagnetic fabrics (measured with high field torque magnetometer), neutron texture and microstructural analyses. The ferrimagnetic and AMS fabrics are similar, indicating that the ferrimagnetic minerals dominate the AMS signal. The paramagnetic fabric is different from the previous ones. Based on the crystallization timing of the different mineralogical phases, the paramagnetic fabric appears related to the upward flow, while the ferrimagnetic fabric rather reflects the late-stage of dyke emplacement and cooling stresses.
\end{abstract}

(C) 2014 Elsevier B.V. All rights reserved.

\section{Introduction}

The high sensitivity and rapid measurements made anisotropy of magnetic susceptibility (AMS) one of the most applied and powerful tools to assess the petrofabric, even for low anisotropy rocks (see, Borradaile and Henry, 1997; Borradaile and Jackson, 2010; Hrouda, 1982; Tarling and Hrouda, 1993). Despite these advantages, it was soon recognized that AMS interpretation is not always straightforward. The superposition of magnetic fabrics, related to magnetic carriers with normal and inverse fabric, or with distinct preferred orientations and/or shapes, is one factor that can result in a whole-rock AMS fabric that does not reflect the true preferred orientation of minerals (Borradaile and Henry, 1997; Chadima et al., 2009; Fanjat et al., 2012; Ferré, 2002; Hirt and Almqvist, 2012; Lamali et al., 2013; Potter and Stephenson, 1988; Rochette, 1988; Rochette et al., 1999; Silva et al., 2008; Tarling and Hrouda, 1993).

To decompose composite magnetic fabrics complementary experimental methods (e.g., anisotropy of magnetic remanence and high-field torque magnetometry) and analytical and computational solutions have

\footnotetext{
* Corresponding author. Tel.: + 351 918986811, + 351 217500000x28328. E-mail address: pmfsilva@fc.ul.pt (P.F. Silva).
}

been developed to separate sub-fabrics (e.g., Banerjee and Stacey, 1967; Callot and Guichet, 2003; Ferré et al., 2004; Jelinek, 1996; Kratinová et al., 2006, 2010; Henry, 1983, 1997; Henry and Daly, 1983; Hrouda and Jelinek, 1990; Martín-Hernandez and Garcia-Hernandez, 2010; Martín-Hernandez and Hirt, 2001, 2004; McCabe et al., 1985; Moreira et al., 1999; Roperch and Taylor, 1986; Schmidt et al., 2007; Stephenson, 1980; Stephenson et al., 1986).

More recently, rock magnetic fabrics studies start to be complemented by quantitative microstructural and crystallographic preferred orientation analyses in order to better understand the rheological behaviour of rocks (e.g., Bascou et al., 2005; Boiron et al., 2013; Cifelli et al., 2009; Machek et al., 2014 this volume; Závada et al., 2007).

The aim of this paper is a better understanding of intrusive processes. This requires recognition of how a dyke's petrofabric records different strain regimes, due to the evolution of stress fields and thermal gradients during magma emplacement and cooling. Different rock minerals crystallize at different times and likely under variable stress fields. Recognizing petrofabrics of individual minerals that are related to different episodes of mineral crystallization during magma emplacement is therefore a key approach. To this aim, we employ a combination of microstructural and textural approaches (neutron diffraction ND, and image analyses to obtain crystallographic preferred orientation $\mathrm{CPO}$ ) with analyses of magnetic fabrics in low and high fields (AMS for 